J. M. Davidson queries how much of the behavioural effects of steroids occurs by action of the steroid at the brain itself-and answers: part only. With each well-investigated steroid, evidence was offered for direct action at the central nervous system, and further actions from peripheral organs. It is thus valuable that measurements can often be made in small quantities of blood of the relevant hormones. V. D. Ramírez describes determinations of luteinizing hormone and follicle-stimulating hormone in $0.2 \mathrm{ml}$. of plasma from rats by radioimmune assay.

The book carries prominently both behavioural and electrophysiological consequences of steroid actions in developing and in adult animals. Most papers are well-documented, but with figures awkwardly placed for consultation: not in the relevant text, but following it. Production and indexing of the book are good, and its discussion sections are plentiful and informative.

H. McIllwain

\section{Fruit Fly}

Drosophila. By Bryan Shorrocks. Pp. 144. (Ginn: London, October 1972.) $£ 2.25$.

Drosophila melanogaster is once again a popular beast in biological research laboratories, especially those devoted to developmental and biochemical genetics; it never did lose its popularity with the population geneticist.

This text by Dr Shorrocks will be useful to anyone starting to work with Drosophila since it provides a succinct and clearly written guide to general biology, laboratory culture, field ecology, methods of collecting, behaviour and elementary cytology. There is also a section devoted to elementary genetics with some suggestions for experiments suitable for the beginning student, but the most valuable single feature is the illustrated diagnostic key and ecological notes relating to a score or so of the commoner species found in Britain. It is ironic that even for species which have been widely used in genetic studies, little is known about their primary breeding sites, population sizes, fluctuations in numbers, distribution, and so on. The British fauna includes a group of closely related species like subobscura, ambigua, tristis, obscura and subsilvestris, whose population biology would certainly repay study. No doubt their similarity in appearance has hitherto often proved discouraging, but Dr Shorrocks's key and clear line diagrams have removed this obstacle and should stimulate comparative studies on the population ecology of these and other British species. F. W. ROBERTSON

\section{Seeds}

Seed Biology. Edited by T. T. Kozlowski. Volume I. Importance, Development and Germination. Pp. xiii +416 . (Academic: New York and London, May 1972.) $\$ 26.40$.

THE first volume of Seed Biology is subtitled Importance, Development and Germination. It is part of a threevolumed work, the second of which will cover germination control, metabolism and pathology; the third will deal with applied aspects of the subject including insects, seed collection, storage, testing and certification. This first volume, then, is really meant to be seen as part of a larger work, and this is made clear by several references within its six chapters to material in subsequent volumes.

The whole work is introduced by T. T. Kozlowski (the editor) and C. R. Gunn in a short chapter dealing primarily with the significance of seeds in evolution, their great diversity and their importance to man. This is followed by two chapters on the development of seeds, concentrating mainly on anatomical aspects; $H$. Singh and B. M. Johri consider the gymnosperms and S. P. Bhatnagar and Johri the angiosperms, Both are worthy accounts which distil an enormous amount of information from a large number of references-nearly 350 in the case of angiosperms.

The fourth chapter by $\mathbf{A}$. Fahn and Ella Werker is an interesting and straightforward description of the anatomical mechanisms of seed dispersal and, in spite of the large number of cases considered, they conclude that the principal types of device serving seed dispersal are quite small. The style and objectives of chapter 5 on the morphogenesis of seed germination by G. P. Berlyn contrast with the rest of the book. Instead of attempting an encyclopaedic coverage, the author has decided to take two contrasting genera, $Z e a$ and Pinus, and give a critical (and very readable) consideration which relates the anatomical and sub-cellular changes in seeds to the wider problems of morphogenesis.

Finally there is a chapter by B. M. Pollock and E. E. Roos on seed and seedling vigour. This is a wide-ranging account of a difficult subject-a difficulty which arises ir: part because of the lack of precision often attached to the term "vigour". Nevertheless, there are some interesting ideas here.

One cannot form a final judgment of a volume which is only one-third of a complete work, but there is little doubt that seed research workers will find it a useful reference book. Most chapters are designed primarily for a specialist audience, in spite of the publisher's blurb; it is unlikely, for example, that they will be of interest to seed growers, as is claimed. The production is very fine and the illustrations are good and lavish - and so they should be, considering the price. I shall look forward to seeing the subsequent volumes.

E. H. ROBERTS

\section{Operational Research}

Operational Research: Techniques and Examples. Edited by G. H. Mitchell. Pp. ix +275 . (The English Universities: London, 1972.) $£ 3.95$.

THIs book is based on material used in the training programme of the Operational Research Executive of the National Coal Board, a programme now mounted jointly with Brunel University as a Master's Course, and follows the publication of a similar book ${ }^{1}$ some ten years ago.

It contains chapters on all the major techniques associated particularly with OR: linear programming and its extensions, dynamic programming, decision theory and theory of games, networks, queues, stock control, replacement, and simulation. As such, it does not differ greatly from many other introductory books on OR, although the editor has managed to pack a lot of material into the 200 or so pages. Brief descriptions of many extensions of the basic techniques are given (for example, postoptimality analysis and parametric programming, decomposition, stochastic programming, separable programming, integer and mixed integer programming are covered in fifteen pages), together with further references, which will provide a good basis for an introductory course, but which will be tough going for the unsupported reader.

The editor has aimed to keep the mathematical level within the reach of anyone with "A" level mathematics, but the liberal use of algebraic notation is likely to make comprehension difficult for the reader who has not progressed beyond that level.

Each chapter is provided with a number of problems and worked answers, amounting to some fifty pages in total. The book is certainly a good candidate for selection as the main reference for an introductory course on $O R$.

ROBERT HARRIS

${ }^{1}$ Houlden, B. T. (editor), Some Techniques of Operational Research (The English Universities Press, 1962).

\section{Addendum}

IN the bibliography to the review of the book, The Careless Technology (Nature, 240, 268; 1972), the publisher was given as The Natural History Press: Garden City, New York. The book is also published by Tom Stacey, London. 